A continuación, nos sitúa en el momento histórico que se vivía en la ciudad de Málaga durante el primer tercio del s. XVIII, cuando se disfrutaba de un esplendor económico y una prosperidad que contribuyeron a la proliferación de fundaciones religiosas. La de San Felipe Neri, en concreto, existe en Málaga desde 1739. A partir de ahí se narran todas las fases por las que pasó el edificio y sus múltiples usos. La Memoria histórica finaliza con un apartado dedicado a las pinturas murales (estilo, autores, fechas), a la arquitectura y ornamentación y al programa iconográfico.

Por otro lado, un nuevo botón permite acceder a la información relativa a la Técnica de ejecución de las pinturas murales del patio, con referencias al soporte de las pinturas y de los elementos pétreos, es decir, las columnas y escudos del patio.

El siguiente enlace proporciona acceso a la Analítica, apartado en el que se describe el análisis químico de los materiales y el estudio de la superposición de capas de las pinturas murales realizados en el Instituto Vicente Espinel, como medio precisamente para el conocimiento de la técnica de ejecución. En este sentido, se especifican las técnicas de análisis empleadas (microscopía óptica o electrónica, espectroscopía, cromatografía), los resultados, tanto relativos a la preparación o base de las pinturas como a las capas de color, y las conclusiones.

En cuanto al botón Estado de conservación, hace referencia en primer lugar a la patología sufrida por el conjunto de forma global y las consecuencias en el estado general de conservación en el momento de iniciar la intervención para, a continuación, describir de forma detallada los problemas de las pinturas murales (soporte, base de preparación, película pictórica, estrato superficial e intervenciones anteriores) y de los elementos pétreos.

En último lugar, sin tener en cuenta el botón dedicado al equipo de trabajo, se analizan los Tratamientos a los que se sometió el conjunto artístico. Este apartado comienza con la definición de los criterios aplicados a la intervención, que se realizó con el objetivo fundamental de lograr recuperar tanto el elemento histórico y documental como los valores estéticos.

Posteriormente, se describen las diferentes fases de los tratamientos de las pinturas murales y de los elementos pétreos, desde los trabajos auxiliares previos hasta la redac- ción de la memoria final, pasando por la documentación o la limpieza.

Finalmente, y a modo de orientación a los posibles destinatarios de la información contenida en este CD-ROM, cabe decir que contiene unos textos muy extensos, un tanto excesivos para tratarse de un formato electrónico (con la consiguiente lentitud en la navegación), en los que a veces los caracteres no destacan con claridad del fondo. Es decir, no se trata de un producto ágil en el que se haya hecho hincapié en el diseño. No obstante, como fuente de información, es importante resaltar que se trata de un documento muy completo, por lo que probablemente cumpla mejor su función como herramienta útil para otros profesionales del ámbito de la restauración que como medio de difusión de la labor realizada por una institución a un público más amplio.

Requerimientos técnicos del CD-ROM:

- Tarjeta de sonido

- Pentium 200

- Windows 95

- SVGA

- CD-ROM $\times 20$

- $32 \mathrm{MB}$

María Victoria Madrid Díaz Centro de Documentación, IAPH

\title{
Exposiciones en la web sobre pintura mural del medievo francés
}

En Internet, podemos encontrar algunos sitios donde se muestra información pormenorizada sobre pinturas murales que han marcado hitos en la historia del arte. Algunos casos concretos como el de Artehistoria.com, alberga información muy detallada sobre grandes genios de la pintura y personajes destacados de la historia, donde se realiza un análisis a todo color, a lo largo de seis galerías de imágenes, sobre los frescos de la Capilla Sixtina, pintados por Miguel Angel Buonarroti en el Cinquecento italiano, con detalles ampliados de cada uno de ellos, así como datos biográficos de su autor y descripción estilística e iconográfica. Todo ello con una muy buena calidad gráfica.
Asimismo, existen otros ejemplos destacados de pintura mural como es el caso de algunos webs que se dedican al análisis del fresco de La Última Cena pintado por Leonardo da Vinci en el Convento de Santa Maria delle Grazie en Milán, donde aparte de su temática, descripción técnica e interpretación, se dedican algunos espacios a analizar y comentar tanto textual como gráficamente, el polémico proceso de restauración que tras 20 años concluyó en 1999.

Pero, tras esta breve introducción, donde no se podía dejar de hacer mención a estos interesantes ejemplos cuyas direcciones daremos al final, el caso que pasamos a anali- zar de un modo más exhaustivo en este número es el de las exposiciones virtuales sobre pintura mural que alberga el Web del Ministerio de la Cultura y la Comunicación de Francia.

El contenido es de sumo interés por su rigor científico, en cuanto a la interpretación, análisis, realización de los recorridos y reproducción fotográfica de las obras.

El acceso a las exposiciones virtuales se encuentra en el índice temático del Web del Ministerio de la Cultura de Francia. Dentro de las mismas, aparecen agrupados por temáticas especializadas distintos museos imaginarios 

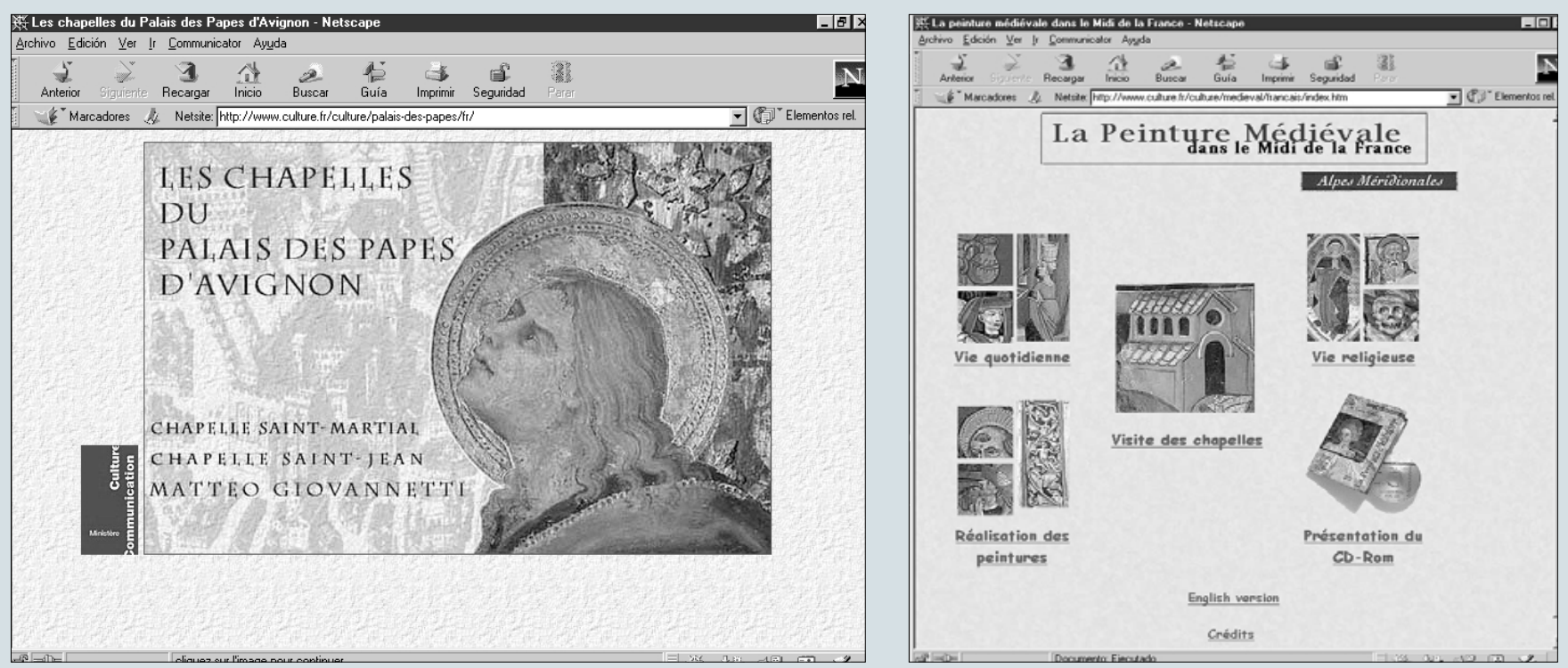

donde podemos visualizar desde nuevas exposiciones, arquitectura o arte contemporáneo, hasta escritos, imágenes, música, objetos de arte y pintura, siendo este último el destino de nuestro análisis y comentario.

Pues bien, dentro de esta opción, encontramos distintos capítulos destinados a estudiar de forma independiente la pintura a lo largo de diversas épocas y temas.

Los dos capítulos que analizaremos en profundidad son los dedicados a Las Capillas del Palacio de los Papas de Avignon, trabajo realizado en 1999 y Las Pinturas Medievales en Los Alpes Meridionales (Sur de Francia), información ejecutada en 1996.

Todos los capítulos, así como todo el web desde un primer momento está escrito en francés, y son estudios realizados por distintos equipos de trabajo cuyos créditos se muestran al final de cada uno de ellos.

Accedemos a Las Capillas del Palacio de los Papas de Avignon a través de una portada que sirve de presentación al capítulo. Una vez dentro, encontramos un índice general de contenidos que cuenta con una introducción sobre las capillas, realizando un primer acercamiento a través de una pintura mural a lo que podía ser la vida en el interior del palacio. También existen apartados dedicados a las capillas que se analizan, otro al pintor de los frescos, Matteo Giovannetti, bibliografía especializada, información sobre un CD-ROM que se ha publicado, y finalmente, los créditos de autoría y un enlace a un web que muestra recorridos turísticos por el palacio de los papas.

Si nos adentramos en las capillas, tenemos un índice específico para la Capilla de SaintMartial, y otro para la Capilla de Saint-Jean.

Es importante señalar que el análisis que se realiza de las mismas es exclusivamente pictórico, además de contar con una breve reseña sobre la vida del titular de cada capilla.

Al lado de una imagen del santo que da nombre a cada capilla, aparece el alzado de la misma donde se localizan, identificándolas con distintos colores, las pinturas situadas en las bóvedas (rosa), registro superior (naranja) y registro medio (morado).

Si picamos en el botón que nos lleva a cada una de las partes, accedemos a una vista panorámica de las pinturas que albergan, todo ello con una calidad gráfica y una rapidez de carga excelente.

En la imagen general de la bóveda, se señala la ubicación de los frescos norte-sur, este-oeste. Asimismo, de izquierda a derecha, alrededor del recorrido panorámico y según su ubicación, identificados con un número, encontramos los títulos de los distintos episodios que forman parte de todo el grupo mural.

Accediendo a cada uno de ellos, entramos en una breve reseña de la escena que se representa y la fotografía del espacio que ocupa dentro del conjunto. A este detalle también se accede pulsando en la parte correspondiente de la vista global. La imagen ampliada de todas las escenas, así como la calidad de detalles que se muestra de los frescos, es excelente, pero lo más destacado es la forma en que se ha resuelto la visita virtual de las pinturas, situando en todo momento al visitante de un modo difícilmente igualable en el espacio real, por la óptima localización y visualización de los frescos.

Para la ejecución del desarrollo panorámico, se ha realizado durante tres meses una campaña fotográfica en las dos capillas, utilizando técnicas especiales para conseguir una visita global de alta resolución, siguiendo un minucioso proceso de numeración y localización de las mismas dentro de la escena.

Otro capítulo de gran interés por lo novedoso de su contenido es el que se le dedica al autor de los frescos de las dos capillas: Matteo Giovanetti, donde se dan datos curiosos sobre su figura en el mundo religioso del momento y las distintas obras que realizó para los Papas, así como un análisis textual y gráfico de la técnica empleada en la realización de los frescos, novedades llevadas a cabo en su ejecución, y un estudio comparativo entre las pinturas de las dos capillas.

El otro capítulo que también nos muestra una interesante y pormenorizada informa- 
ción para el conocimiento de las pinturas del momento, es el dedicado a La Pintura Medieval en los Alpes Meridionales, en el Sur de Francia.

En la presentación del capítulo aparecen distintas entradas, donde se analizan las pinturas desde un punto de vista sociológico, costumbrista y religioso, desglosando aspectos tales como la vida cotidiana o la vida religiosa del momento, tomando como punto de partida las imágenes que, a través de las pinturas, nos han llegado de la época. También encontramos otras secciones complementarias que analizan los aspectos técnicos y estilístico de las pinturas así como una visita a todas las capillas que albergan pinturas dentro de las regiones de los Alpes Marítimos y del Var.

La primera sección es la que nos comenta la vida cotidiana de la época a través de los objetos, las actividades domésticas, las vestimentas, los útiles o herramientas y los tocados, así como del modo de sentarse a la mesa y de comer. Todos los capítulos vienen acompañados de pinturas murales que nos muestran gráficamente todos estos detalles. Pinchando en cada una de ellas podemos acceder a la imagen ampliada y a ciertos detalles de las mismas.

La siguiente sección está dedicada a analizar la vida religiosa del momento, mostrando al igual que en la anterior, ejemplos de algunas pinturas que dejan ver las arraigadas raíces religiosas de la época medieval, destacando la gran devoción existente a los Santos, el fuerte culto a la Virgen, los nuevos temas que iban surgiendo en la pintura religiosa del momento, y la gran inquietud que se tenía por el destino del hombre, ejemplificado con escenas del Juicio Final, El Paraíso, El Infierno o El Purgatorio.

Dentro de todos estos capítulos generales, existen subcapítulos que profundizan aún más sobre cada uno de los aspectos principales como por ejemplo, dentro del apartado dedicado a los Santos, las actividades más frecuentes de los mismos, escenas de contenido dogmático en el caso del culto a la Virgen, o Los Santos protectores y escenas narrativas dentro del apartado destinado al Destino del Hombre.

\section{FICHA DE LA WEB}

URL PRINCIPAL: MINISTERIO DE LA CULTURA Y LA COMUNICACIÓN DE FRANCIA: http://www,culture.fr URL DE LAS CAPILLAS DEL PALACIO DE LOS PAPAS DE AVIGNON: http://www,culture.fr/culture/palais-despapes/tr/index.html

URL DE LA PINTURA MEDIEVAL EN LOS ALPES MERIODINALES (VERSIÓN FRANCESA):

http://www,culture.fr/culture/medieval/francais/index.htm

URL DE LA PINTURA MEDIEVAL EN LOS ALPES MERIODINALES (VERSIÓN INGLESA):

http://www,culture.fr/culture/medieval/en//index.htm

CRÉDITOS/AUTORES DEL CAPÍTULO SOBRE LAS CAPILLAS DEL PALACIO DE LOS PAPAS DE AVIGNON:

Dirección Científica: Marie-Claude LEONELLI, Sophie KOVALEVSKY Centre International de Documentation et de Recherche du Petit Palais d'Avignon

Introducción: Dominique VINGTAIN, conservador del palacio de los papas de Avignon

Producción y Realización: Serge BRIEZ, Dominique PIAU. ART'HIST

Fotografías: SergeBRIEZ-C Serge BRIEZ-ART`HIST 1999

Producción: Ministère de la Culture et de la communication. Mission de la recherche et de la Technologie.

CRÉDITOS/AUTORES DEL CAPÍTULO SOBRE LA PINTURA MEDIEVAL EN LOS ALPES MERIDIONALES:

Dirección Científica: Centre International de Documentation et de Recherche du Petit Palais d'Avignon. Sophie Kovalevsky, Marie-Claude Léonelli,

Ministère de la Culture

Concepción del Cd-Rom: Serge Briez, ART'HIST Éditions; Aurélie Delbey, Ministère de la Culture

Realización: Aurélie Delbey

Fotografías: (C) Serge Briez

Procesamiento de Imágenes: Serge BRIEZ and Aurélie DELBEY

Versión Inglesa: Carole Jouron

Coordinación y Medios Técnicos: Ministère de la Culture, Mission de la Recherche et de la Technologie,

Département de l'Organisation et des Systèmes d'Informational

NFORMACIÓN DISPONIBLE: Muy buena: Pormenorizada.Científica

CALIDAD GRÁFICA: Excelente

DISEÑO WEB: Óptimo

FACILIDAD DE NAVEGACIÓN: Muy buena

VELOCIDAD DE CARGA: Muy rápida

CALIDAD GLOBAL: Muy buena

\section{OTRAS DIRECCIONES DE INTERÉS SOBRE PINTURAS MURALES}

FRESCOS DE LA CAPILLA SIXTINA: http://www.artehistoria.com/genios/pintores/gal2750-1.htm LA ÚLTIMA CENA DE LEONARDO DA VINCI: DESCRIPCIÓN TÉCNICA Y FORMAL:

http://www.moon.inf.uji/es/ leonardo

LA ÚLTIMA CENA DE LEONARDO DA VINCI: COMENTARIOS SOBRE SU RESTAURACIÓN:

http://www.arsmedia.nect/cenacolovinciano/english.htm

El apartado dedicado a la realización de las obras, analiza las pinturas murales según las diferentes técnicas empleadas en la ejecución de las mismas, ya fueran estas realizadas al fresco (buon fresco), mezzo fresco, secco o pintura a la cal. Asimismo se analizan los motivos decorativos de los murales desde el punto de vista iconográfico, el estilo y la manera de resolver la figuración del espacio. Todo ello acompañado con ejemplos.
El apartado final está dedicado a las capillas decoradas con pinturas murales de los Alpes Marítimos y del Var, mostrando un mapa sensible con la situación de las mismas dentro de las regiones, donde se sitúan los iconos que representan a los santos titulares. Pinchando en ellos, accedemos a las páginas que nos muestran información sobre las cuatro capillas que se analizan. 
Se explica que la situación de las capillas viene justificada por ser una ruta natural de penetración en el país desde el mar hacia los Alpes.

De cada una de ellas se dan datos arquitectónicos y estilísticos acompañados de una fotografía, de la planta y del análisis de algunos murales destacados. Finalmente se añade bibliografía general y reseñas de estudios específicos sobre el tema.

Tanto las fotografías de las capillas como los dibujos de las plantas tienen acceso al detalle ampliado.

Todas las secciones están conectadas entre sí, bien por enlace entre ellas, o por las flechas que te dirigen con facilidad a la página anterior o posterior, así como al índice general.

De igual modo, a través de iconos situados en la parte superior de cada página existe una interconexión entre todas las secciones del capítulo. Ello permite que en todo momento esté presente el hilo conductor del análisis, sin perder de vista la visión global.

En definitiva, cabe destacar la gran profundidad y el rigor científico que conlleva el análisis de los temas, lo que permite conocer a través de las pinturas todos los aspectos que marcan la vida social y cultural del momento

Este capítulo, sí muestra una versión en inglés, así como, al igual que en el primer caso, datos sobre su autoría.

Cabe decir que ambos capítulos se encuentran editados en Cd-Rom, información que también se contempla de forma muy clara en la Web. Los dos forman parte de una Enciclopedia de la Pintura Medieval dentro de la Francia Meridional, en dos volúmenes distintos. Del volumen dos, que es el dedicado a los Alpes Meridionales, se muestran en Internet algunas páginas con instrucciones sobre como consultar el catálogo, cómo abrir una imagen, o cómo hacer una búsqueda en la base de datos que contiene.

En conclusión, los dos capítulos son excelentes en cuanto al nivel de desarrollo de la información, al bien resuelto recorrido por las imágenes, a la exhaustividad y profundidad en el tratamiento de los temas y a la excelente calidad gráfica, lo que demuestra una vez más que en Internet existen, al contrario de lo que pueden opinar algunos, información muy válida para documentarse de un modo novedoso, serio y científico; información, en definitiva, dirigida a un público especializado que exige documentos serios que aporten datos de interés a la cultura y al saber.

Susana Limón Rodríguez Centro de Documentación del IAPH

\section{Información bibliográfica sobre Pintura Mural}

En la siguiente bibliografía se recoge una selección tanto de monografías como de artículos publicados a partir de 1990, sobre estudios históricos-artísticos de Pintura mural, técnicas de conservación y restauración, así como intervenciones llevadas a cabo principalmente en Andalucía. Los títulos marcados con asterisco se encuentran disponibles para su consulta en la Biblioteca del $\mathrm{IAPH}$.

- ABASCAL FUENTES, Juan. Las pinturas murales de la Basílica de la Macarena: obra del pintor sevillano Rafael Rodríguez Hernández. Boletín de Bellas Artes, 1991, nº XIX. Sevilla: Patronato José María Quadrado. C.S.I.C., p. 105-I22.

- ADMETLla, Carmina, CARRERAs, Anna, PEDRAGOSA, Nuria. Plan de actuación: Consolidación y preservación de la pintura mural. Butlleti del Museu Nacional d'Art de Catalunya, 1999., n 3, p. III-115.*

- AGUILAR, Juan [et al.]. Pinturas murales y elementos pétreos del Instituto Vicente Espinel de Málaga: Restauración, estudio histórico-artístico, estudio científico. [Málaga]: Junta de Andalucía, Consejería de Cultura, D.L. 1999. (Conservación. Monografías). *

- AGUILAR GUTIÉRREZ, Juan, ARENILLAS, Juan Antonio. Las pinturas murales de la fachada de la Iglesia de Santa María la Blanca de Sevilla y su restauración. Atrio. Revista de Historia del Arte, 1996, nº 8-9, p. 37-51. *

- AGUILAR GUTIÉRREZ, Juan, MARTíNEZ MONTIEL, Luis Francisco. Las pinturas murales del Museo de Bellas Artes de Sevilla y su restauración. Laboratorio de Arte, 1992, tomo 2, n. 5, p. I1-34. *
- Aguilar gutiÉRREZ, Juan, martíneZ MONTIEL, Luis Francisco. Las pinturas murales de la sacristía de la Catedral de Jaén y su restauración. Atrio. Revista de Historia del Arte, 1996, n 8-9, p. I13-119. *

- ARCOS VON HAARTMAN, Estrella. (Coord.). Retrato de la Gloria: Restauración del Altar Mayor de la Catedral de Málaga. Barcelona: Winterthur, 1999.

- ASENJO RUBIO, Eduardo. La memoria olvidada. Aproximación al patrimonio pictórico mural de Ronda: siglo XVIII. Boletín de Arte, 1999, n²0, p. 525-545. *

- ASENJO RUBIO, Eduardo, LANZAS BURGOS, Jesús. Las arquitecturas pintadas del barroco en Málaga [Archivo de ordenador]. Málaga: Universidad de Málaga, Departamento de Historia del Arte, 1999. * 